\title{
AS CARACTERÍSTICAS DA PISTA DE CORRIDA DO JOCKEY CLUBE DO PARANÁ
}

\author{
The Jockey Club of Parana (Brazil) Horse Racetrack \\ Characteristics
}

\author{
Leandro Pinto Boldrini ${ }^{1}$ \\ Adriana Busato ${ }^{2}$ \\ Marcelo Cabral Jahnel
}

\section{Resumo}

Este artigo tem como objetivo avaliar as características encontradas na pista de corrida do Jockey Clube do Paraná em junho de 2006 e possibilitar futuras informações capazes de substanciar outros trabalhos concernentes ao melhoramento do desempenho e saúde dos animais que a utilizam, bem como em outras áreas de tráfego de cavalos.

Palavras-chave: Pista de areia; Jockey Clube do Paraná; Corrida de cavalos.

\section{Abstract}

This article has as objective to evaluate the Jockey Club of Parana Racetrack characteristics - Brazil, in June 2006, and provide additional data to subsidize other similar studies related to the horse's performance and health, as well as in other areas of horse's traffic.

Keywords: Racetrack; Jockey Club of Parana; Horserace.

1 Acadêmico do Curso de Ciências Eqüinas da PUCPR, 1_boldrini@yahoo.com.br, Rua Gago Coutinho, 453 - Curitiba - PR - Brasil.

2 Professora Orientadora - Médica Veterinária - M.Sc, haras_fb@harasfb.com.br, Rua Clóvis Bevilaqua,300 - ap. 401 Curitiba, PR, Brasil.

3 Colaborador - Engenheiro Agrônomo - Dr./ M.Sc, marcelo.jahnel@pucpr.br, Rua Abilio Peixoto, 323 ap. 24, Curitiba, PR, Brasil. 


\section{Introdução}

Independente do Esporte Eqüestre a ser realizado, da raça do cavalo que estiver competindo, da habilidade do cavaleiro e do cavalo, um dos fatores comuns a todos sempre será a pista, local onde esse cavalo irá demonstrar suas habilidades. Hoje os órgãos responsáveis no Brasil pelas provas eqüestres somente atentam em padronizar a classificação do piso da pista: se essa é de areia, grama, saibro, entre outros, e dimensões a serem utilizadas em cada esporte, porém não tem sido encontrado padrão relacionado ao material utilizado para compor essas pistas, bem como uma metodologia padronizada de suas construções. Por conta disso, cada entidade organizadora de prova a nível oficial estabelece o padrão que bem entender.

Levando em consideração que a maioria das pistas de esportes eqüestres oficiais no Brasil é de areia, esse trabalho tem como objetivo caracterizar a pista de areia usada atualmente no Jockey Clube do Paraná, facilitando posteriormente maiores estudos relacionados à formação, manutenção e conservação das pistas que utilizam os mesmos princípios e materiais na sua construção.

\section{Materiais e métodos}

Para o desenvolvimento desse trabalho, foram utilizadas duas etapas, sendo a primeira um questionário dirigido a três tipos de profissionais que atuam diretamente no Jockey Clube do Paraná: treinadores, jockeys e veterinários; e análises laboratoriais para a determinação da granulometria da areia, teor de umidade na curva e na reta e quantidade de areia existente na curva e na reta.

\section{Resultados e discussão}

Resultados referentes à pista e as condições climáticas:

Encontrou-se aqui uma diferença na pista em relação ao seu estado. Em dias secos e sem chuvas, a pista se torna seca, o que provoca algumas dificuldades no manejo dos animais. A grande presença do pó causa o aumento de casos de doenças pulmonares nos animais e jockeys, que inalam a poeira constantemente. Encontrou-se também uma falta de aderência e firmeza na pista para os animais trabalharem, onde esses afundam os membros na areia, fazendo muito mais força que o normal para manter a velocidade. Com isso, o rendimento dos animais tende a cair e há um provável aumento de lesões por uma necessidade de esforço maior.

Em dias de muita chuva, encontramos uma pista em estado encharcado. Um acúmulo de água muito grande na pista demonstrou uma provável deficiência na sua drenagem. A condição de uso nesse perfil de pista, segundo seus usuários, é a pior possível. Além do acúmulo indesejado de água na pista, o aparecimento de inúmeros buracos, devido a uma falta de manutenção, é grande. A presença desses buracos torna o trabalho do jockey e do treinador ainda mais complicado, pois inúmeros animais se lesionam de alguma forma ou até mesmo se fraturam por pisarem nos buracos. Outra característica desse perfil de pista é também a força que os animais têm que fazer para trabalhar. Devido à falta de areia em alguns trechos (FIGURA 1), a base da pista acaba exposta, e pela pista estar encharcada e o solo dessa base ser de origem argilosa, esse material acaba aderindo nos cascos dos cavalos, fazendo com que eles tenham de fazer mais força para se moverem, como no caso da pista seca e é justamente essa força em excesso que pode machucar os animais. Outro ponto bem frisado pelos profissionais é o grande número de cavalos que, ao treinar nesta condição de pista, retornam com lesões nos machinhos (sob os boletos), acarretando custos com tratamentos. 
FIGURA 1 - Falta de areia no trecho da reta entre os $1.200 \mathrm{~m}$ aos $1.300 \mathrm{~m}$. Figure 1 - Lack of sand in the straight stretch between 1,200 $\mathrm{m}$ and 1,300 $\mathrm{m}$.

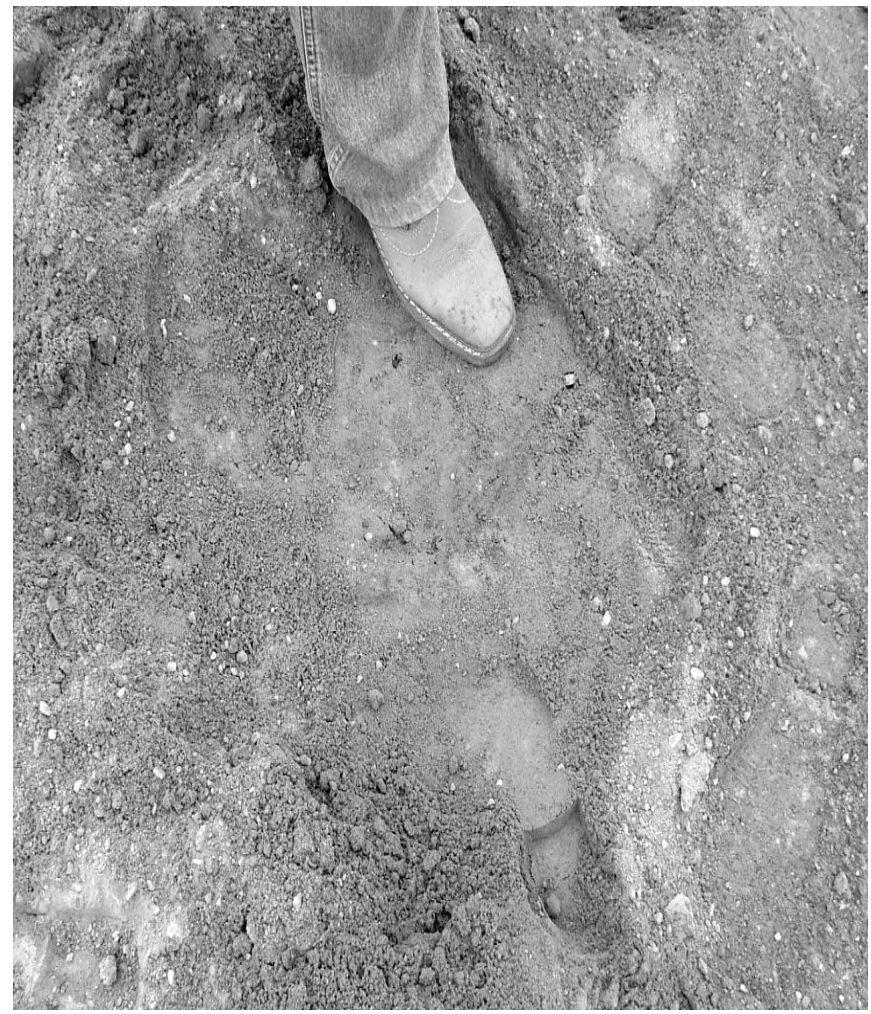

O terceiro perfil de pista analisada é o que chamamos de pista molhada. Nesse perfil de pista, essa é irrigada até que chegue ao padrão esperado para sua melhor utilização. Encontramos esse perfil também quando chove de forma moderada, onde a chuva apenas umedece a pista. Nesse tipo de pista, o problema do pó praticamente desaparece, as condições da falta de aderência e firmeza são praticamente eliminadas e, por permitir uma melhor manutenção, os buracos não são mais um problema generalizado. Essa seria a condição ideal de trabalho na pista.

\section{Observações referentes ao uso diário da pista e sua manutenção:}

O uso da pista de corrida do Jockey Clube do Paraná é feito diariamente de forma constante, salvo aos Domingos, onde a grande maioria dos animais recebe sua folga semanal. A presença de uma pista lateral exclusiva para treinos é algo muito superficial. Dos entrevistados, todos alegaram que $95 \%$ dos seus animais fazem o trabalho de treino na pista de corrida e não na destinada para treinos, por conta da menor quantidade de areia e falta de manutenção da pista de treino, o que faz com que suas características se tornem perigosas para os animais.

No que se refere ao uso da pista principal, durante as competições, além do que já descrito anteriormente, atentamos ainda aos seguintes pontos levantados pelos jockeys e treinadores:

Primeiro: animais que correm ou correram em pista de grama e vêm disputar corridas em pista de areia naturalmente sentem mais dificuldades e muito raramente mantêm o mesmo tempo que conseguiam na pista de grama; em animais que correram a sua vida inteira em pista de areia e fazem algumas corridas em pista de grama, alguns não voltam a correr como antes na areia e em alguns casos se recusam a correr na areia novamente.

Segundo: animais que foram treinados em pistas onde a base não é composta por concreto e asfalto e vão competir em pistas com essas características, têm que se adaptar à pista - uma vez que a pista com base de concreto e asfalto é mais 
rápida e dura, mas quando se adaptam, em sua maioria são competitivos. O oposto já não é verdadeiro. Animais que sempre correram em base de concreto e asfalto e que nunca correram em pistas com base argilosa, mesmo após período de adaptação, em sua grande maioria não são tão competitivos com animais que foram preparados ou que sempre correram nas pistas de base mais mole. Outro dado importante é que a porcentagem de animais com lesões nas pistas com base de concreto e asfalto é muito mais alta. No que se refere à manutenção da pista, há um descontentamento generalizado. As características percebidas em relação às pistas com condições climáticas são, em sua maioria, um reflexo da falta da manutenção adequada. A pista seca, se mo- lhada de uma forma eficiente, se tornaria uma pista molhada, o que é o perfil realmente procurado. Se houvesse manutenção da pista encharcada com grades e rolos, não se acumulariam os buracos, amenizando muito as lesões nos animais. Nota-se ainda a presença de pedras (FIGURA 2), que se faz freqüente na extensão da pista devido ao tráfego dos animais atingirem a base com muita facilidade e as trazerem para a superfície da pista. Outro ponto de crítica da pista é com relação ao mecanismo de irrigação existente atualmente (FIGURA 3). O equipamento não consegue ter pressão suficiente para irrigar toda a pista e molha apenas metade da raia, deixando ainda poças de água na frente do irrigador, encharcando a pista nesses trechos.

FIGURA 2 - Pedra encontrada ao lado do rastro de um cavalo (trecho da reta entre os $1.300 \mathrm{~m}$ aos $1.200 \mathrm{~m})$.

Figure 2 - Rock found on the side of the horse footprint (straight stretch between 1,200 $\mathrm{m}$ and 1,300 $\mathrm{m}$ ).

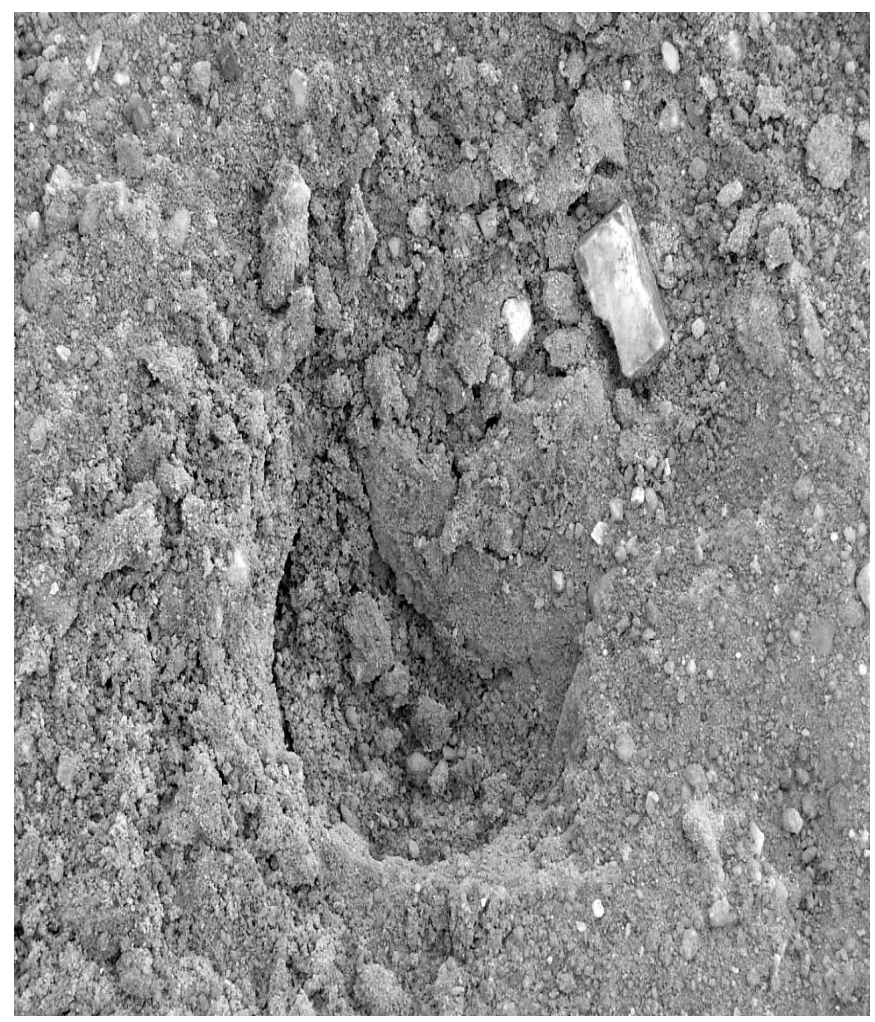




\section{FIGURA 3 - Sistema de irrigação usado no Jockey Clube do Paraná.}

Figure 3 - Irrigation system used in the Jockey Club of the Parana.

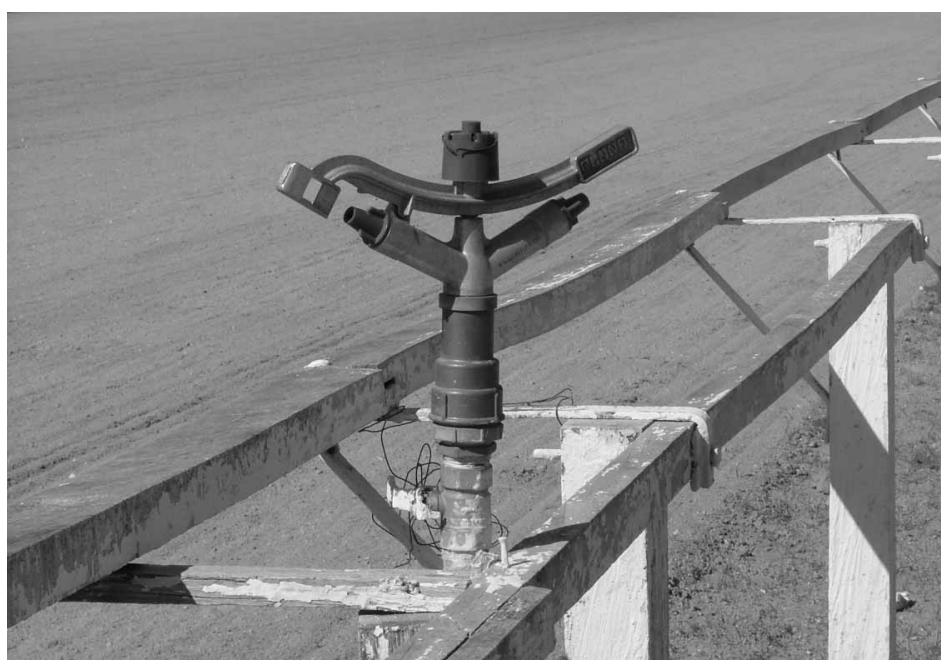

\section{Resultado da análise granulométrica:}

Foram percebidas diferenças na granulometria da areia nos pontos analisados, como mostram os gráficos (FIGURAS 4 e 5 ). Nota-se um aumento na porcentagem dos grãos maio- res: entre $1,3 \mathrm{~mm}$ a $0,59 \mathrm{~mm}$, no centro da pista, tanto na reta como na curva. Os grãos que compreendem uma granulometria menor, entre $0,42 \mathrm{~mm}$ a menores que $0,25 \mathrm{~mm}$, encontram-se em maior quantidade nas extremidades da pista.

FIGURA 4 - Diferenças na granulometria na reta, dos $1.200 \mathrm{~m}$ aos $1.300 \mathrm{~m}$.

Figure - Differences in the granulometry in the straight stretch, between 1,200 $\mathrm{m}$ and 1,300 $\mathrm{m}$.

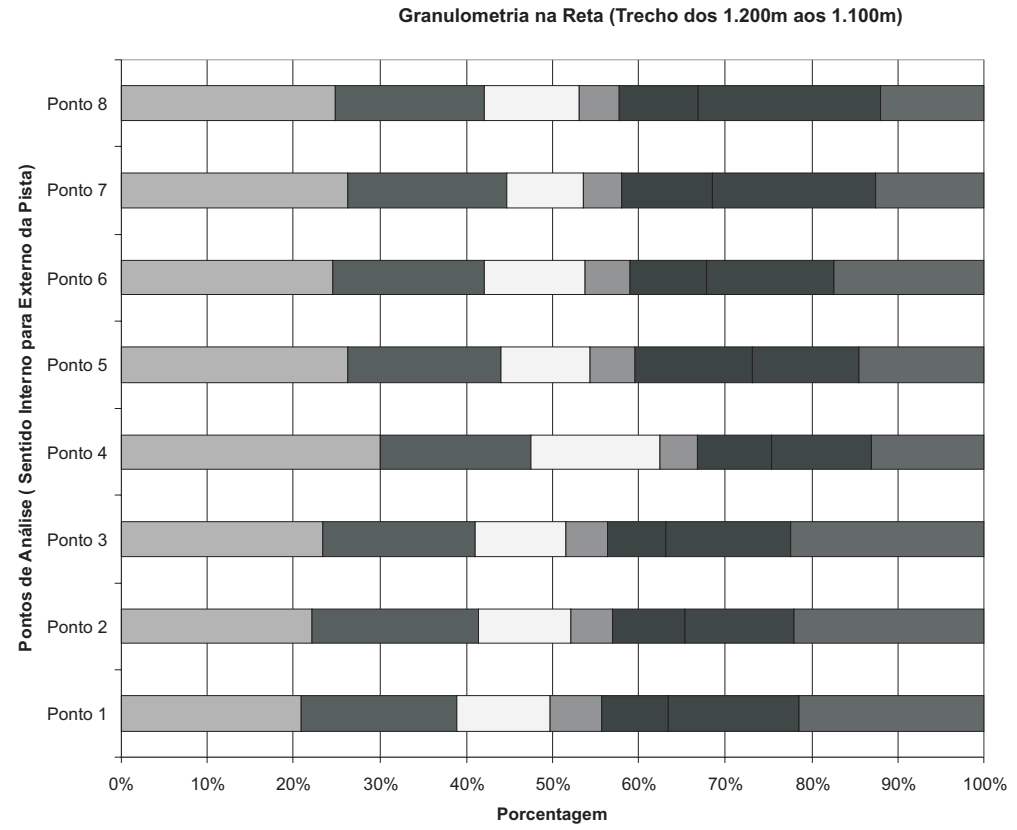


FIGURA 5 - Diferenças na granulometria na curva, trecho dos $800 \mathrm{~m}$ aos $700 \mathrm{~m}$.

Figure 5 - Differences in the granulometry in the curve, stretch between $700 \mathrm{~m}$ and $800 \mathrm{~m}$.

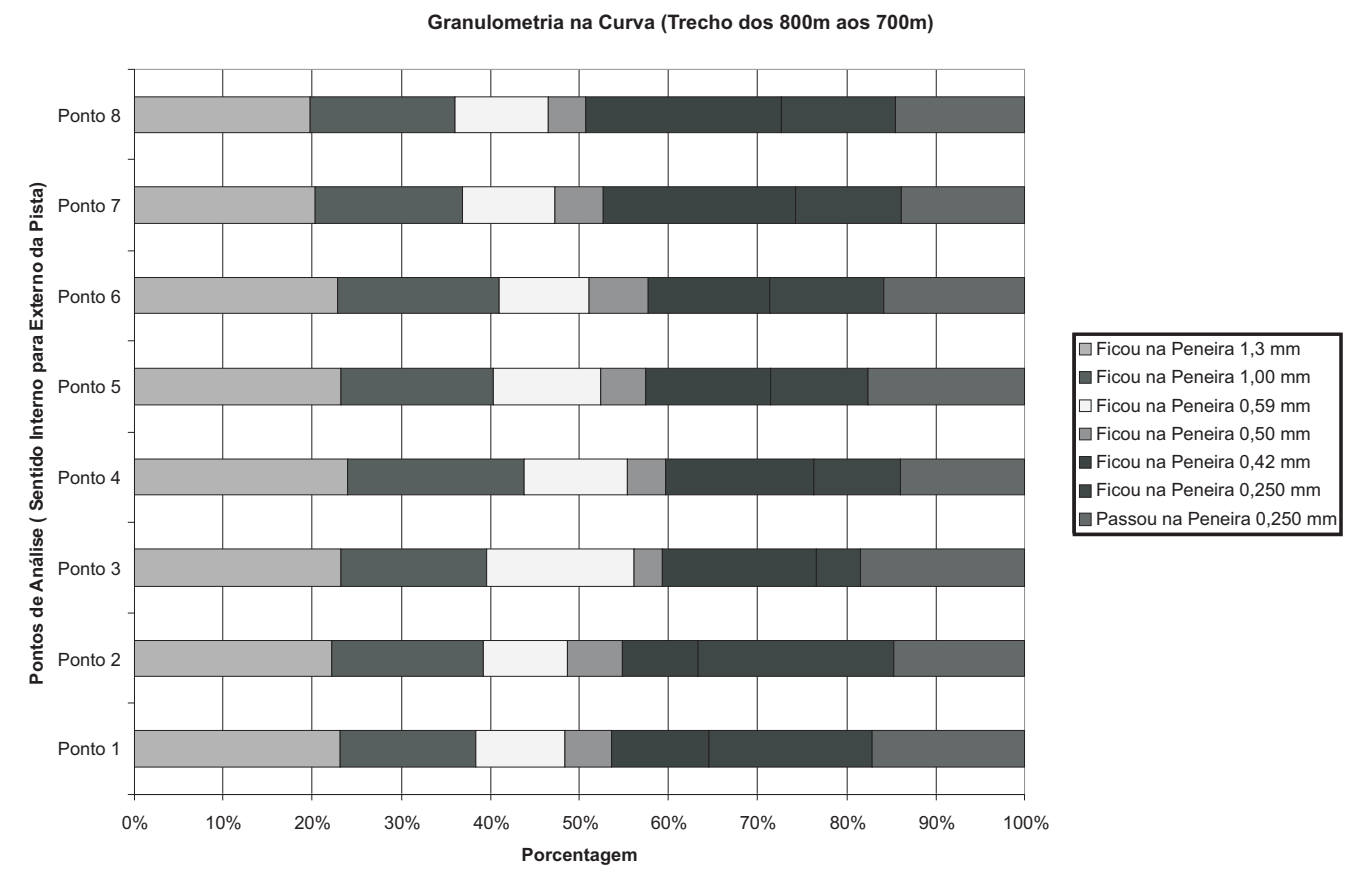

\section{Resultado do teor de umidade:}

Para essa análise utilizou-se um ponto de referência fornecido pelo jockey (trecho da reta dos $200 \mathrm{~m}$ aos $100 \mathrm{~m}$ ) que seria o ponto ideal de uso da pista, com relação à umidade da areia. Com base nessa referência, foi construído um gráfico (FIGURA 6), onde se encontrou um solo mais seco na parte interna da pista, tanto na curva como na reta. Conforme as amostras chegam ao centro da pista, o teor de umidade aumenta. Na curva, encontrou-se um excesso de umidade em um dos pontos próximo à parte externa da pista.

FIGURA 6 - Diferença no teor de umidade encontrado na reta e na curva, comparado com o valor referencial. Figure 6 -Difference in the bumidity proportion found in the straight and curve stretch, compared with the referential value.

Teor de Umidade

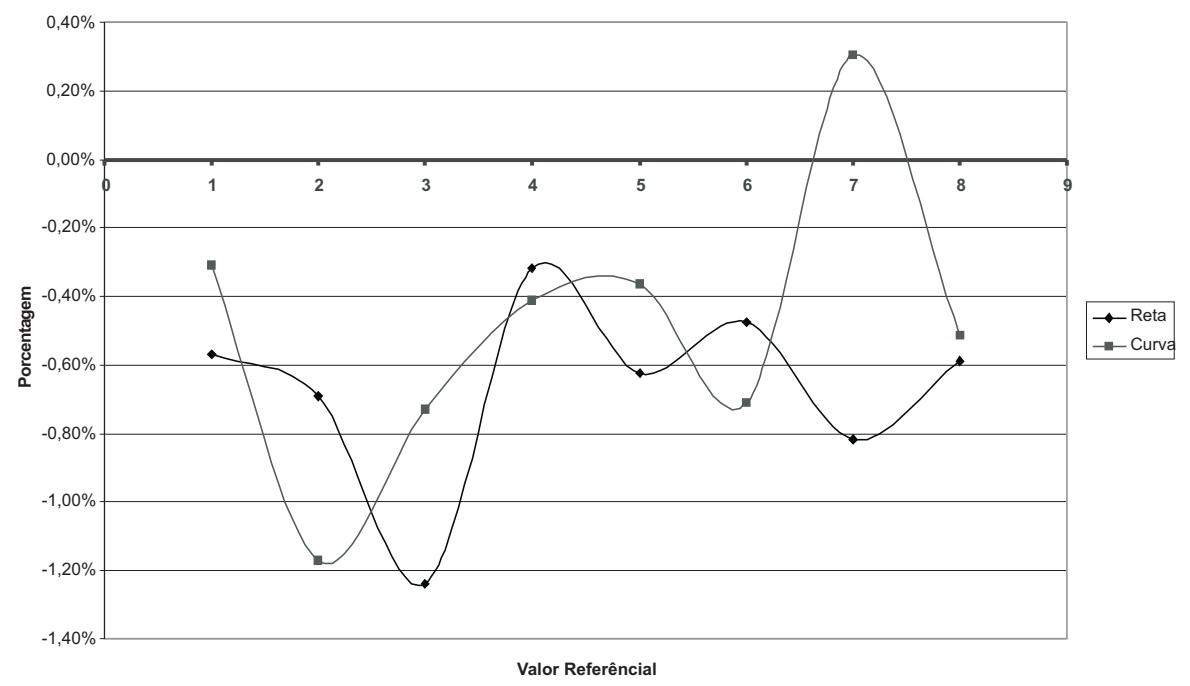




\section{Resultado da quantidade de areia:}

O resultado da análise de campo mostra a quantidade de areia existente em cada local analisado. Existe uma variação por todos os pontos analisados e o ideal seria esse valor se manter estável e o mais próximo possível de um valor que corresponda a uma profundidade confortável para o animal, que seria por volta de 70 mm (LODGE; SHANKS, 1994; YOUFU 2002). Observando os gráficos (FIGURAS 7, 8, 9 e 10), podese fazer uma comparação com os locais analisados e nota-se a falta de areia na parte interna da curva quando comparada à parte interna da reta. Outra característica observada é uma diferença na quantidade de areia encontrada na parte interna da raia em relação à externa (trecho da reta dos $1.400 \mathrm{~m}$ ). Já no trecho da reta dos $1.200 \mathrm{~m}$, essa característica não é observada, onde a quantidade de areia encontrada na parte interna da raia se estende homogeneamente por mais da metade da raia. Nas Figuras 11 e 12, pode-se observar uma comparação entre os locais analisados, no que se diz respeito à quantidade de areia.

\section{FIGURA 7 - Diferença na quantidade de areia no inicio da reta $(1.400 \mathrm{~m}$ aos $1.300 \mathrm{~m})$.}

Figure 7 - Difference in the amount of sand in the beginning of straight stretch (between 1,300 m and 1,400 m).

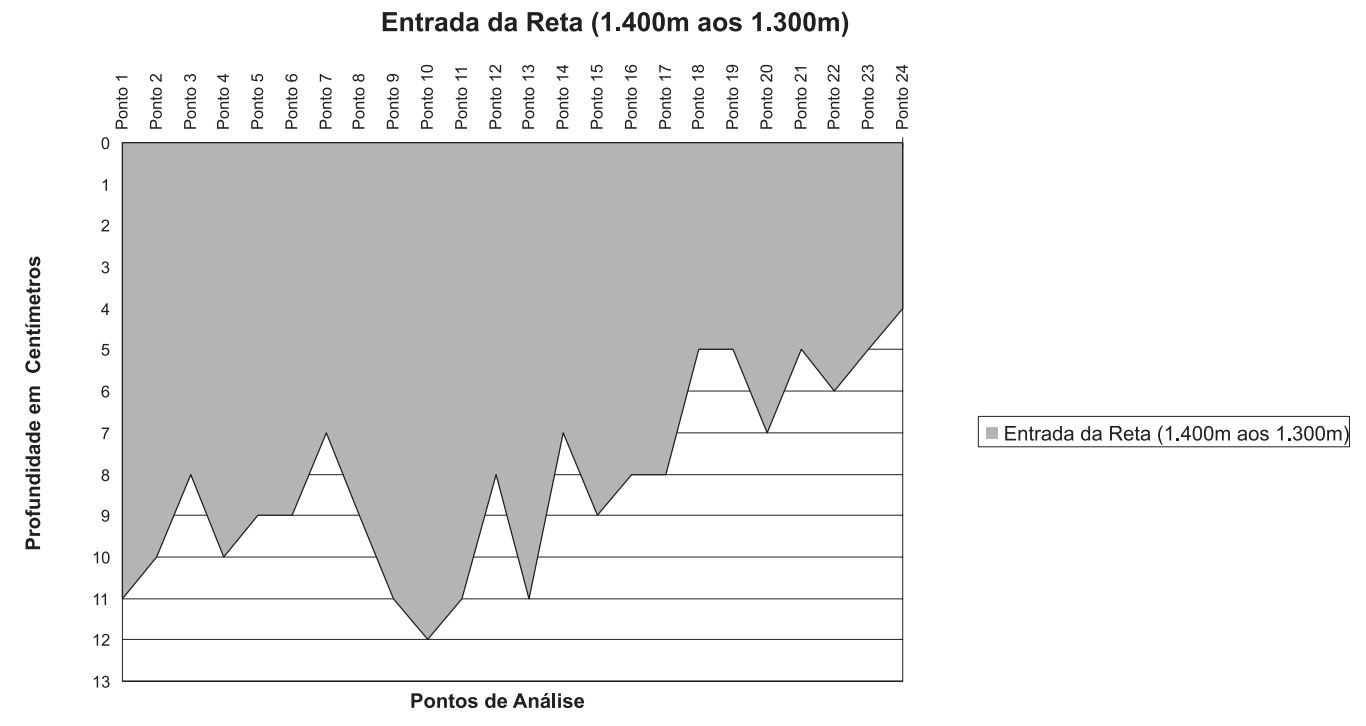

FIGURA 8 - Diferença na quantidade de areia no meio da reta $(1.100 \mathrm{~m}$ aos $1.200 \mathrm{~m})$. Figure 8 - Difference in the amount of sand in the middle of the straight stretch (between 1,100 $\mathrm{m}$ and 1,200 $\mathrm{m}$ ).

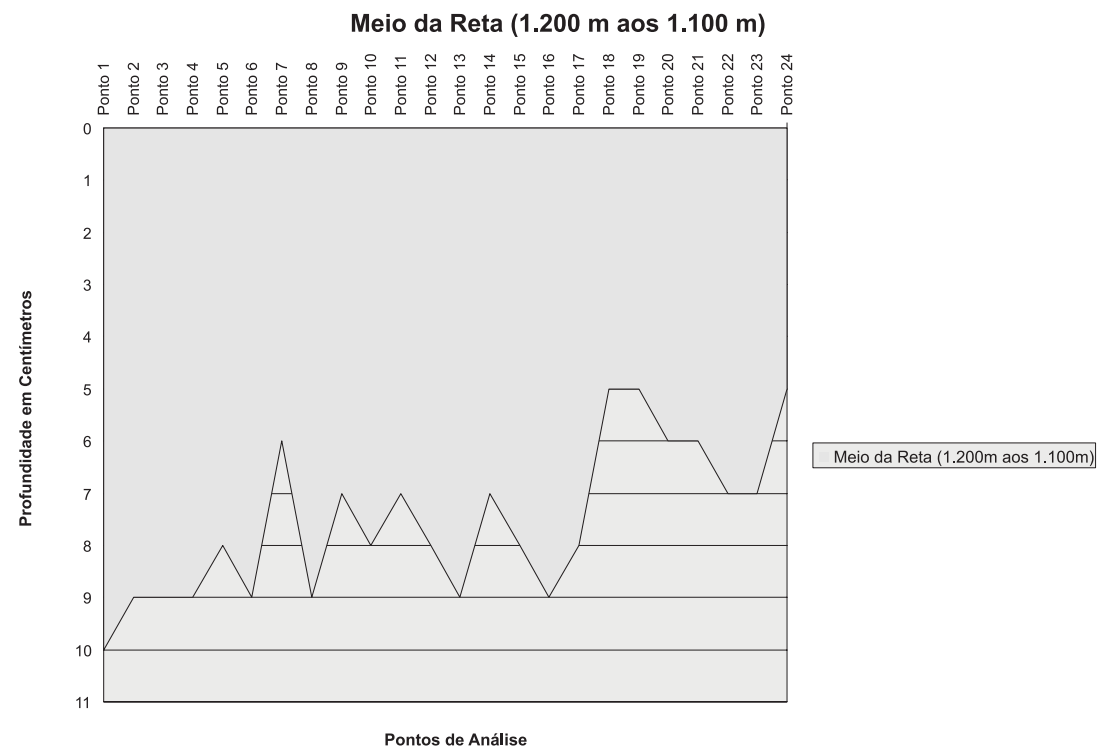


FIGURA 9 - Diferença na quantidade de areia no inicio da curva $(800 \mathrm{~m}$ aos $900 \mathrm{~m})$.

Figure 9 - Difference in the amount of sand in the beginning of the curve (between $800 \mathrm{~m}$ and $900 \mathrm{~m}$ ).

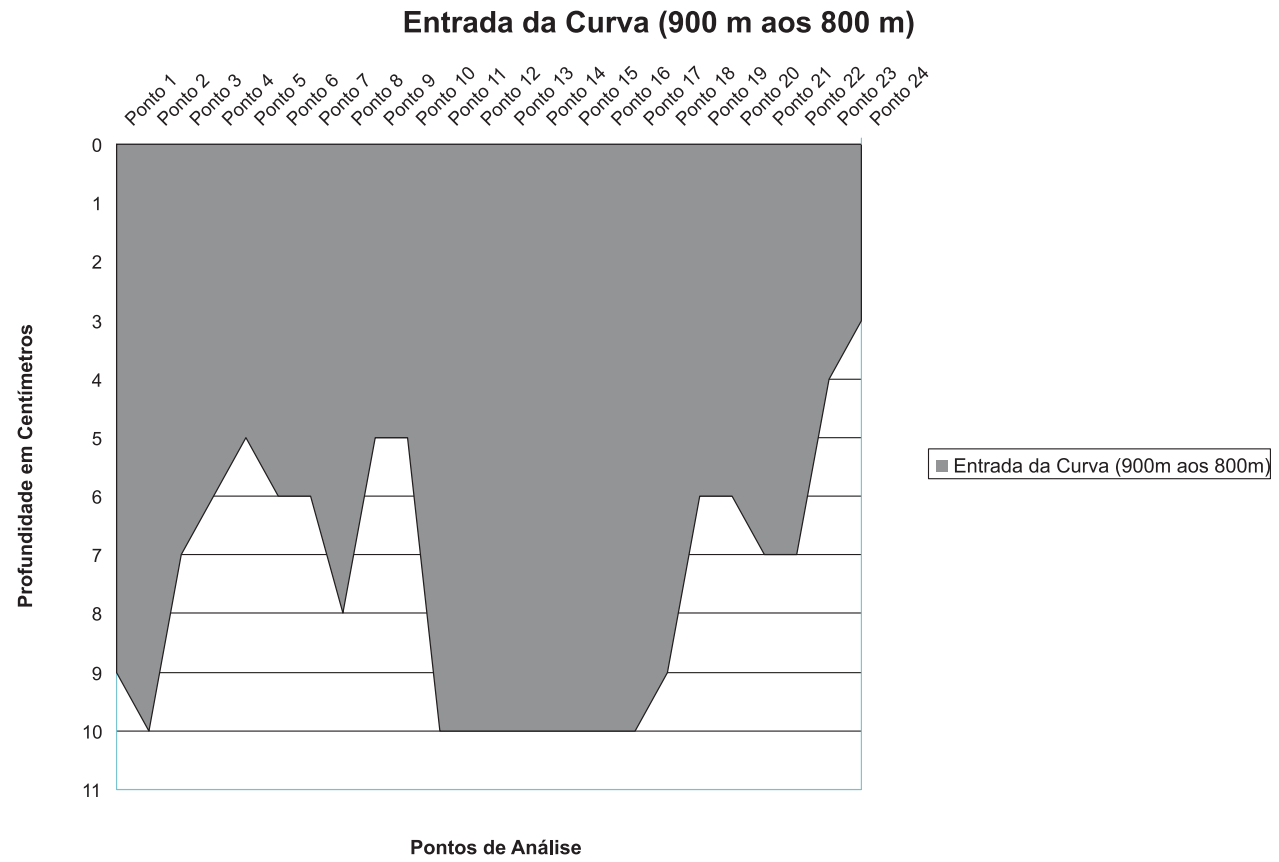

FIGURA 10 - Diferença na quantidade de areia no meio da curva $(700 \mathrm{~m}$ aos $800 \mathrm{~m})$.

Figure 10 - Difference in the amount of sand in the middle of the curve (between $700 \mathrm{~m}$ and $800 \mathrm{~m}$ ).

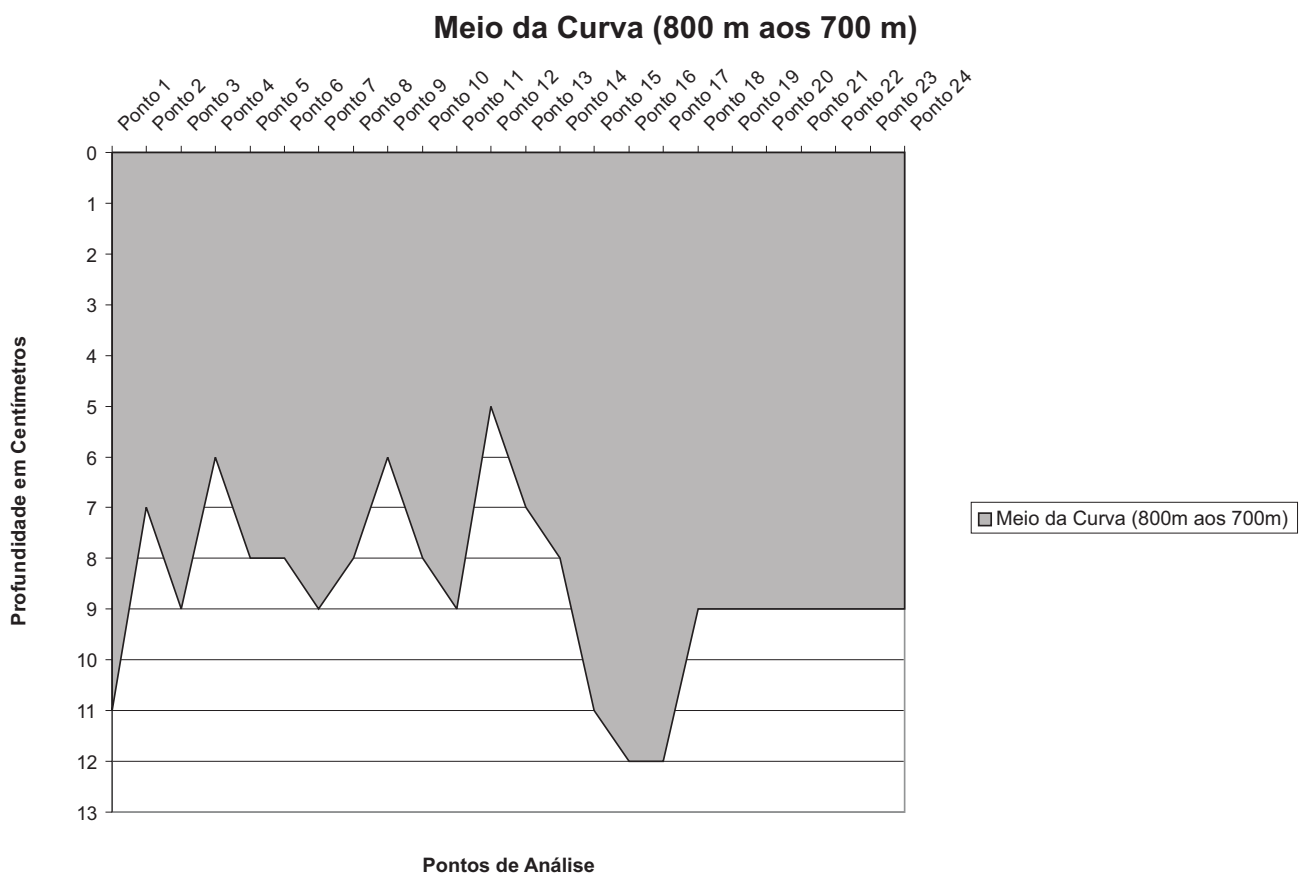


FIGURA 11 - Comparação da quantidade de areia na reta.

Figure 11 - Comparison of the amount of sand in the straight stretch.

\section{Comparação da Profundidade da Areia na Reta}

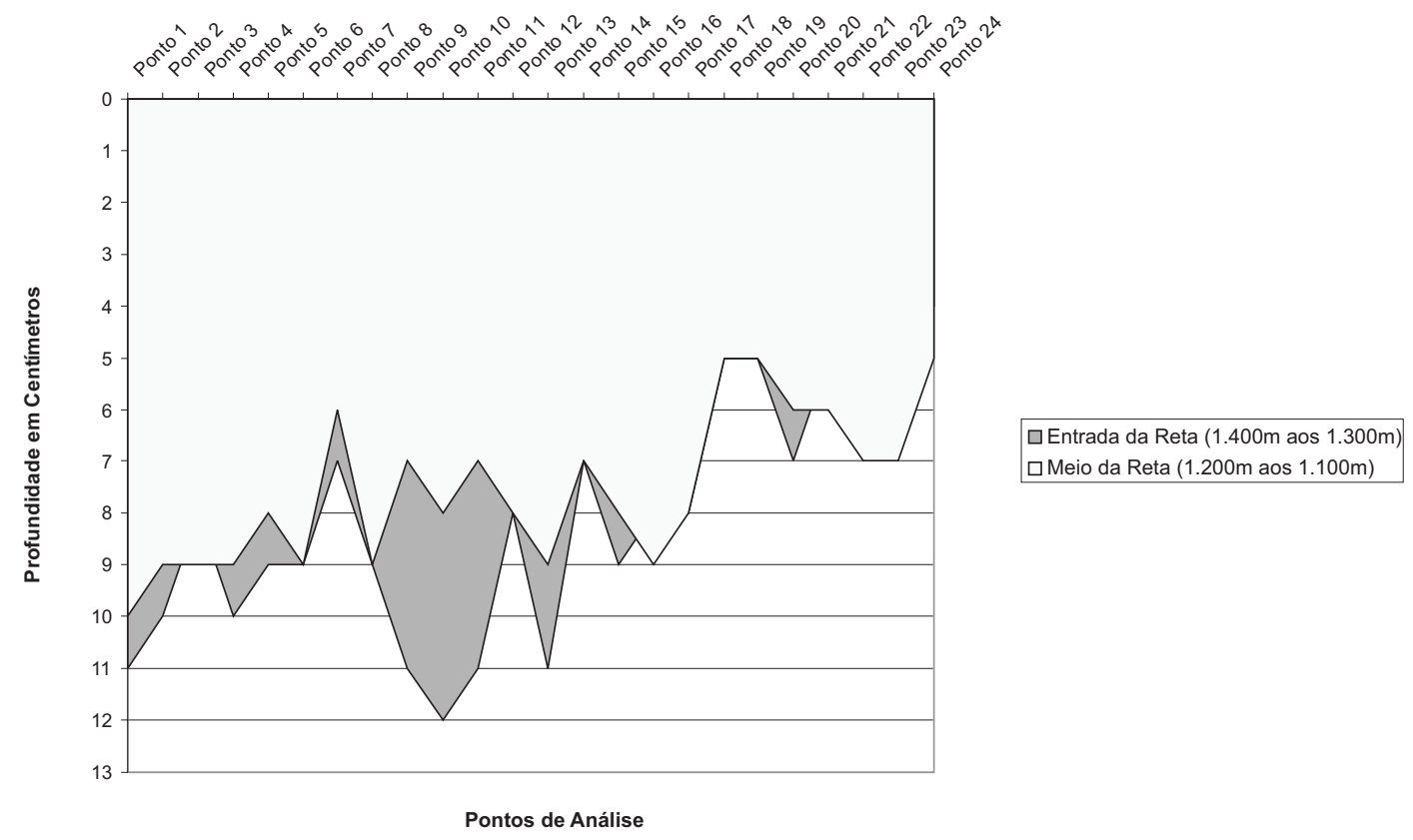

FIGURA 12 - Comparação da quantidade de areia na curva.

Figure 12 - Comparison of the amount of sand in the curve.

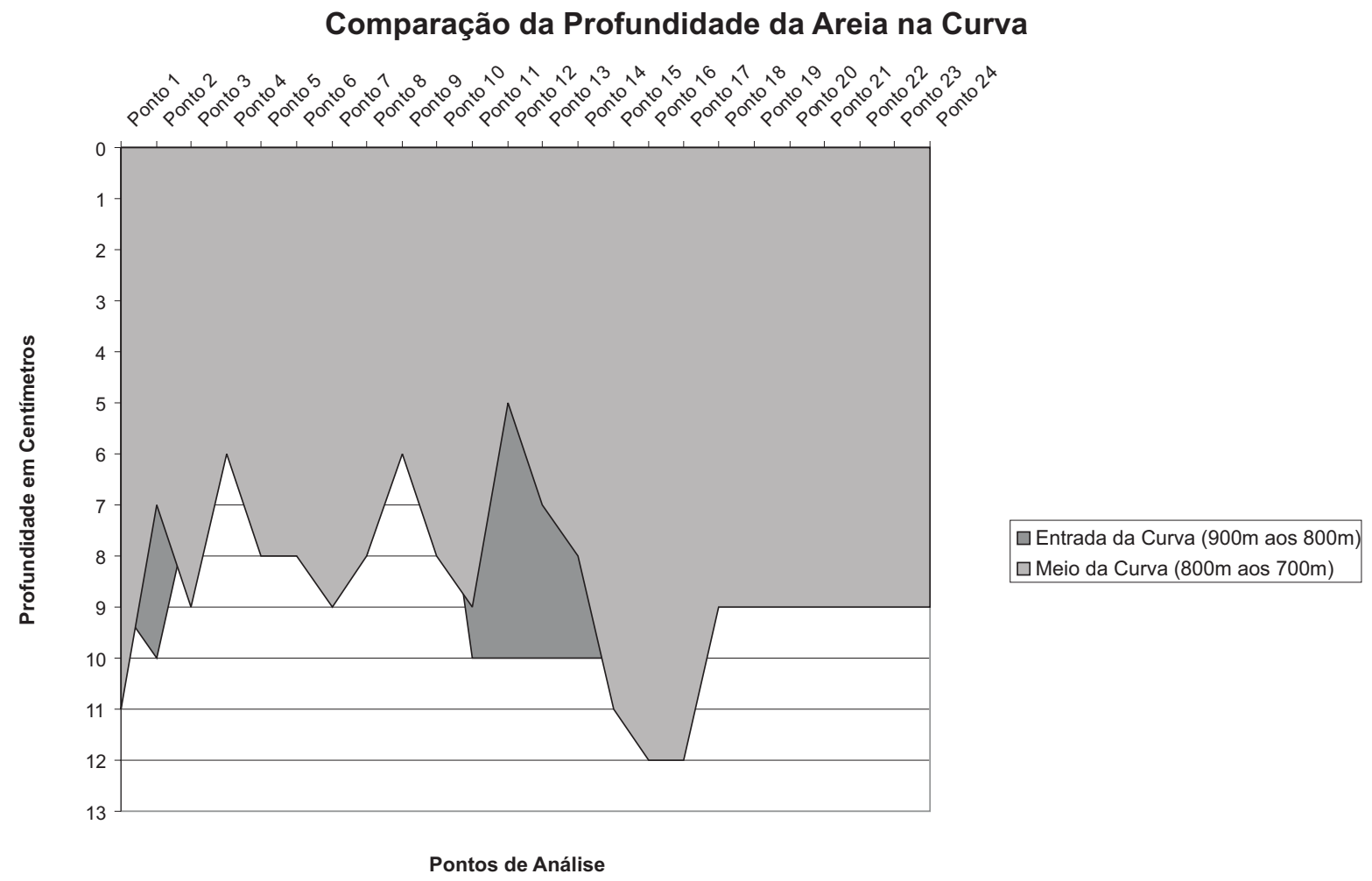




\section{Conclusões}

A importância de uma cooperação entre os usuários e profissionais que utilizam a pista do Jockey Clube e a importância de uma caracterização da pista ficou patente. Sem as informações fornecidas e a experiência de cada grupo profissional entrevistado seria impossível a coleta dos dados corretos.

Com relação aos dados técnicos, foi comprovado que a pista de corridas analisada não é homogênea sob vários aspectos e as diferenças existentes podem prejudicar os animais e usuários da pista. Com a disponibilidade de tal estudo, torna-se possível pontuar os motivos e a localização dos problemas nesta e em outras pistas similares, visando efetivar o seu aprimoramento com investimentos nos pontos problema, e viabilizar sua manutenção a um mínimo custo.

É possível, a partir de tal monitoramento, atingir e manter a pista em condições próximas às ideais para a prática de esportes eqüestres, devido à redução de riscos para os animais de alto padrão genético e alto valor comercial ao viabilizar maior segurança e qualidade da pista avaliada.

\section{Agradecimentos}

À minha orientadora Professora Adriana Busato, pela sua ajuda e incentivo no desenvolvimento do trabalho; ao meu colaborador, Professor Marcelo Jahnel, pela sua paciência, esclarecimentos e ajuda na elaboração do trabalho; e aos profissionais do Jockey Clube do Paraná, em especial ao Sr. Márcio Gusso, Sr. Pedro Nickel Filho, Sr. Emerson Cruz e o Professor Pedro Michelotto, pela colaboração e ajuda na coleta dos dados.

\section{Referências}

LODGE, R.; SHANKS, S. All-Weather Surface for Horses. London: 1994.

YOUFU, K. Stage for the Japan Cup \& Japan Cup Dirt. 2002. Disponível em: < http:// www.jair.jrao.ne.jp/journal/v10n2/j1000f.html > Acesso em: 14 Junho 2006.

Recebido: 25/11/2005

Aprovado: 31/03/2006 